\title{
Decay Factor as a Determinant of Forecasting Models
}

\author{
Grzegorz Mentel $^{1} \&$ Jacek Brożyna ${ }^{2}$ \\ ${ }^{1}$ Department of Quantitative Methods, Rzeszow University of Technology, Rzeszow, Poland \\ Correspondence: Grzegorz Mentel, Department of Quantitative Methods, Faculty of Management, Rzeszow \\ University of Technology, Al. Powstancow Warszawy 8, 35-959 Rzeszow, Poland. Tel: 48-60859-1330. E-mail: \\ gmentel@prz.edu.pl
}

Received: October 10, 2014

Accepted: November 5, 2014

Online Published: December 25, 2014

doi:10.5539/ijef.v7n1p118

URL: http://dx.doi.org/10.5539/ijef.v7n1p118

\begin{abstract}
The present discussion focuses on the significance of historical observations which affect current market situations, and consequently impact short term forecasts. The main purpose of the study is to verify the level of importance and perform ranking of information necessary for estimating Value at Risk. Hence, effectiveness of VaR estimates was assessed in the context of volatility modeling by means of exponentially weighted moving average (EWMA), relative to various levels of decay factor $\lambda$.
\end{abstract}

Keywords: decay factor, value-at-risk, modeling, risk, prediction

\section{Introduction}

Taking into account the fact that risk is an ever-present element of financial decisions taken on a daily basis, and as such it is a significant factor encountered by any economic entity in its operations, it should be emphasized that the phenomenon cannot be eliminated altogether. Yet, in this case it can be quantified, analyzed in detail and controlled; consequently it is possible to perform risk management.

Identification of risk in terms of its nature and range makes it possible to take optimal decisions and possible preventive actions. These are aimed at reducing its scale. Effectiveness of decisions reducing the scale of risk may be varied and it may depend on the method of its quantification and assessment. Therefore, the key issue here is the choice of adequate risk estimation method.

Value-at-risk methodology seems to offer the best approach to risk quantification, and the novel concepts for VaR estimation, which have been developed over the years, to a greater or smaller extent, point towards the scale of potential risks. The choice of the most advantageous concept is the key to success.

In order to gain better understanding of adequacy and effectiveness of VaR estimations it is necessary to examine the relevant determinants. It seems that it is important to record fluctuations in prices of instruments during a specified period in the past and to identify their volatility. Moreover, adequate determination of the confidence level may also be a challenge.

The authors of the present article have discussed the above constituents of Value at Risk in their previous studies (Mentel, 2013a; Mentel \& Brożyna, 2014), and here they want to focus on the so-called information decay process.

\section{Volatility Estimation and Forecasting}

Generally VaR methods can be divided into two groups, i.e. simulation methods and parametric methods.

The former group is characterized by the fact that it does not make any assumptions regarding the form of distribution in the relevant series, and the methods of determining volatility do not use any equations. This is because volatility index is determined by a price change reflecting a quantile equivalent to the required confidence level. Percentile methods, as they are frequently called, are preferred by those who believe the assumption of normal distribution is a weak point in the general VaR model.

Yet, the aforementioned methods contain a significant drawback, since they assume that volatility is constant in time, hence these models assign equal weight to each daily return. This is commonly accepted, yet in the world of finance such volatilities of values are not constant; on the contrary, they are subject to almost continuous change. In fact, financial markets show irregular and frequently abrupt changes in volatility, i.e. a low volatility 
period is followed by a high volatility period (Best, 2000).

Such approach implies the necessity to use other models, and this is justified by the phenomenon of "grouping of incomes gained from financial assets", which involves the fact that incomes on a given day are immediately impacted by economy related information while incomes on the following days are affected less significantly; this means the effects "are distributed" in a relatively short period of time. Autocorrelation leads to the fact that incomes of the recent period provide more information on the current level of volatility than incomes from an earlier period. Hence, we can suggest that in order to obtain a model which will accurately measure the current level of volatility, it is necessary to assign higher weights to recent incomes.

This approach is assumed by the second group of models, including the analytical models which describe "behaviors" of financial instruments in an investment portfolio in various ways.

Generally, we can distinguish here the models developed by J.P. Morgan's group, based on volatility models created by means of exponentially weighted moving average (EWMA) (Crowder, 1987), as well as GARCH (generalized autoregressive conditional heteroskedastic) class models (Bollersev, 1986), (Bollersev, 1987). EWMA is a significant element of the Value at Risk model known as RiskMetrics ${ }^{\mathrm{TM}}$, which is the basic subject of the further discussion.

Equations for deriving the aforementioned volatilities are described as:

$$
\sigma_{t}^{2}=(1-\lambda) r_{t}^{2}+\lambda \sigma_{t-1}^{2}
$$

and

$$
\sigma_{t}^{2}=\alpha_{0}+\alpha_{1} \cdot r_{t-1}^{2}+\beta_{1} \cdot \sigma_{t-1}^{2} ; \alpha_{0}, \alpha_{1}, \beta_{1}>0
$$

Contrary to EWMA models, where parameters are relatively easy to estimate, determination of parameters in the many variations of GARCH class models is not always a simple process, because in order to estimate them it is necessary to maximize the likelihood function. In this case, extreme price changes in a series of data may pose a challenge for the maximum likelihood function, applied here in order to calculate parameters, a problem which is manifested by a lack of convergence.

The essential difference between EWMA model and GARCH class models is the fact that the latter more aggressively than the former responds to changes in time series. An interesting and useful feature of GARCH models is that they take into account the phenomenon of "regression to the mean". This is mainly linked with the fact that the value of some financial assets oscillates around certain long-term values.

\section{Number of Historical Data as a Function of the Decay Factor $\lambda$}

In the classic model of RiskMetrics the so-called conditional variance for daily returns in prices of shares (with their practically assumed mean value equal zero) is calculated as infinite moving average with exponential weights:

$$
\sigma_{t}^{2}=\sigma_{t \mid t-1}^{2}=(1-\lambda) \sum_{j=0}^{\infty} \lambda^{j} \cdot r_{t-1-j}^{2}
$$

By approximation, for sufficiently large number of historical observations $(n \rightarrow \infty)$ we can express the relation in the following way:

$$
\sigma_{t}^{2}=(1-\lambda) \sum_{j=0}^{n-1} \lambda^{j} \cdot r_{t-1-j}^{2}
$$

Hence, using the above relationship (4) we can try to determine an effective number of historical observations.

The number is generated in such a way that the sum of weights for finite moving average (equal $1-\lambda^{n}$ ) constitutes appropriately high percentage: $1-\gamma_{t o l}$ of the sum of weights for theoretical infinite moving average (which equals 1 ), where: $0<\gamma_{t o l}<1-$ is a sufficiently low level of tolerance. We then acquire a relation linking the decay factor, level of tolerance and the required number of historical observations:

$$
1-\lambda^{n}=\left(1-\gamma_{t o l}\right)
$$

From relation (3.22) we can derive the following formula for determining the required number of historical observations, relative to the defined tolerance level and the assumed decay factor (Jongwoo \& Mina, 2001) (Pisula \& Pisula, 2001): 


$$
n=\frac{\ln \left(\gamma_{t o l}\right)}{\ln (\lambda)}
$$

Therefore, adopting the value of standard decay factor $\lambda$ at the level proposed by RiskMetrics ${ }^{\mathrm{TM}}$ and $\gamma_{\text {tol }}$ at the level of 0.01 , for the needs of further analyses we assumed $n=151$ of historical observations, as the number which makes it possible to effectively generate Value at Risk (Figure 1), even though earlier research (Mentel \& Brożyna, 2014) demonstrated that the optimal number of observations necessary for accurate VaR estimations oscillates closer to 100 (Figure 2).

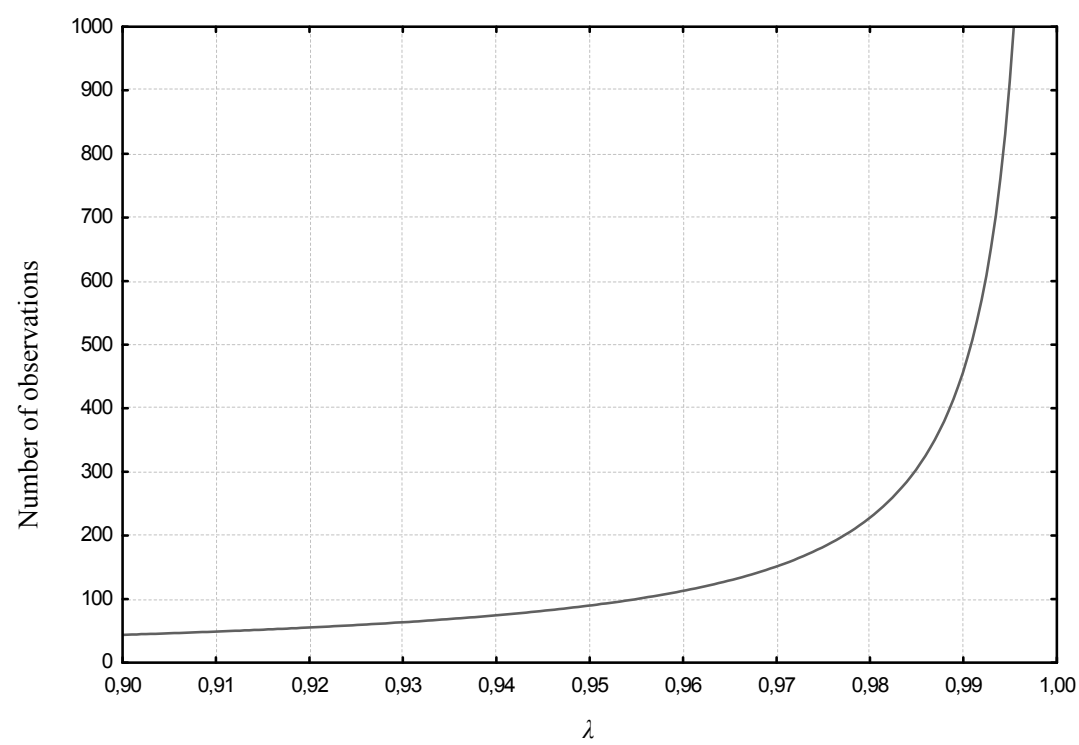

Figure 1. Number of historical observations as a function of decay factor $\lambda$

Source: Elaborated by the authors, based on RiskGrades ${ }^{\mathrm{TM}}$ Technical Document, Second edition, February 2001.

\section{Forms of Analytical Models}

Given the fact that this discussion focuses exclusively on models in which volatility is established by means of exponentially weighted moving average, the investigation was limited to a narrow group of RiskMetrics ${ }^{\mathrm{TM}}$ models. Hence we took into account the classic RiskMetrics NormalDrift model where random noises are modeled using normal distribution, RiskMetrics t-Student model where noises are modeled using Student's t-distribution; RiskMetrics GED where noises are modeled by generalized error distribution, as well as RiskMetrics NormalMixture, where random noises are modeled using the so-called mixtures of normal distributions.

Estimated in accordance with the above model, VaR thresholds (at the accepted level of significance $\alpha$ ) for daily time horizon relative to returns take the following forms, respectively:

$$
\mu+\tau_{N(0,1), \alpha / 2} \cdot \sigma_{t} \leq r_{t} \leq \mu+\tau_{N(0,1), 1-\alpha / 2} \cdot \sigma_{t}
$$

where: $\tau_{N(0,1), \alpha / 2}, \tau_{N(0,1), 1-\alpha / 2}$ - respectively, quantiles of a given row in normal distribution.

$$
\mu+\tau_{t(0,1, v), \alpha / 2} \cdot \sigma_{t} \leq r_{t} \leq \mu+\tau_{t(0,1, v), 1-\alpha / 2} \cdot \sigma_{t}
$$

where: $\tau_{t(0,1, v), \alpha / 2}, \tau_{t(0,1, v), 1-\alpha / 2}$ - respectively, quantiles of a given row in Student's t-distribution.

$$
\mu+\tau_{G E D(0,1, v), \alpha / 2} \cdot \sigma_{t} \leq r_{t} \leq \mu+\tau_{G E D(0,1, v), 1-\alpha / 2} \cdot \sigma_{t}
$$

where: $\tau_{G E D(0,1, v), \alpha / 2}, \tau_{G E D(0,1, v), 1-\alpha / 2}$ - respectively, quantiles of a given row in GED distribution.

$$
\tau_{\text {NormMix }\left(\mu_{1}, \sigma_{1}, 0,1, p\right), \alpha / 2} \cdot \sigma_{t} \leq r_{t} \leq \tau_{\text {NormMix }}\left(\mu_{1}, \sigma_{1}, 0,1, p\right), 1-\alpha / 2 \cdot \sigma_{t}
$$


where: $\tau_{\text {NormMix }\left(\mu_{1}, \sigma_{1}, 0,1, p\right), \alpha / 2}, \tau_{\text {NormMix }\left(\mu_{1}, \sigma_{1}, 0,1, p\right), 1-\alpha / 2}$ - respective quantiles of a given row.

All parameters for specific models $\left(\lambda, \mu, v, \mu_{1}, \sigma_{1}\right.$ p) are determined using the maximum likelihood method.

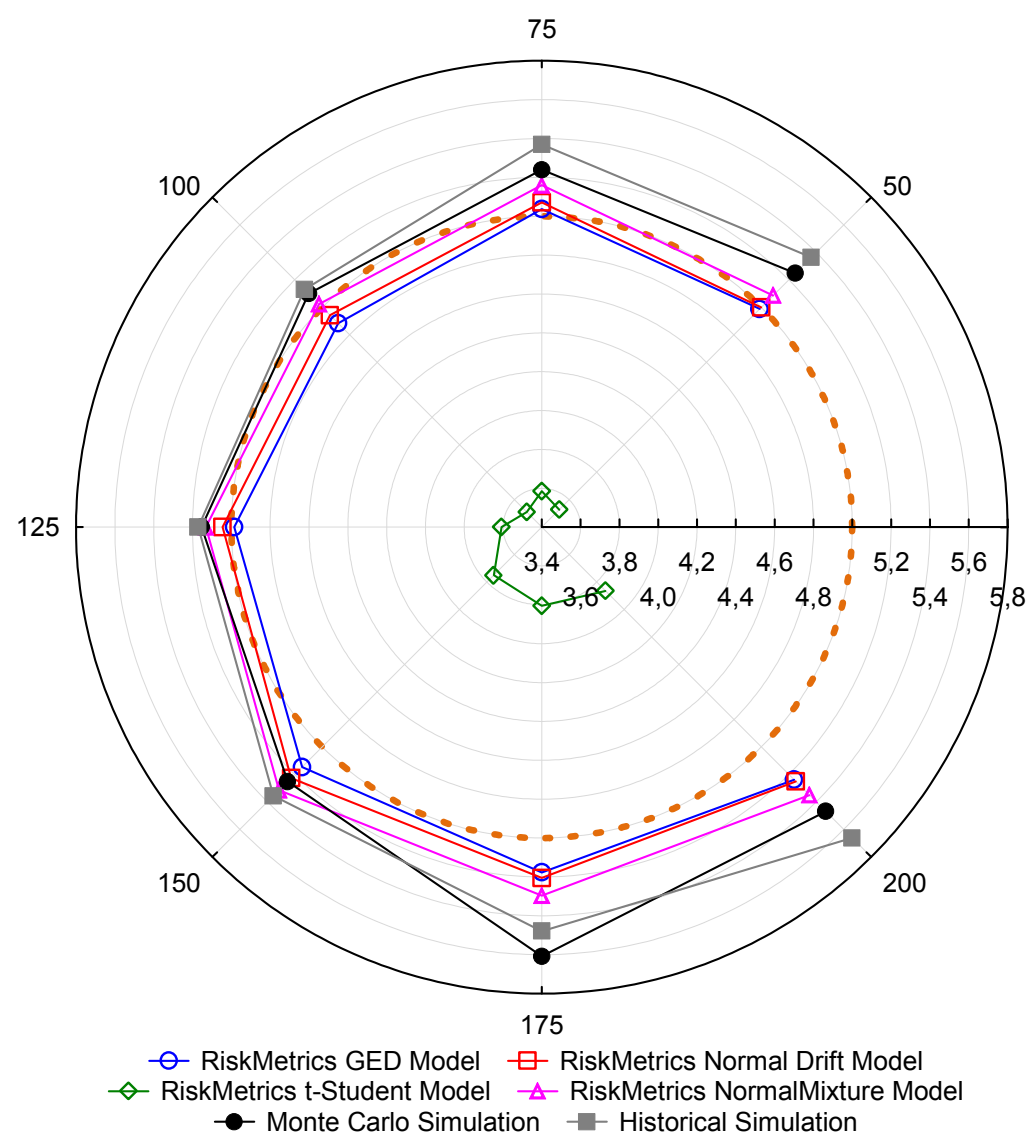

Figure 2. The average value of the percentage of exceedances beyond the $V a R$ values for the different number of historical observations taken into account in their estimation $(\alpha=0.05)$

Source: Mentel G., Brożyna J., Historical Data in the Context of Risk Prediction, International Journal of Business and Social Research, Vol. 3, No. 1, Maryland Institute of Research 2014.

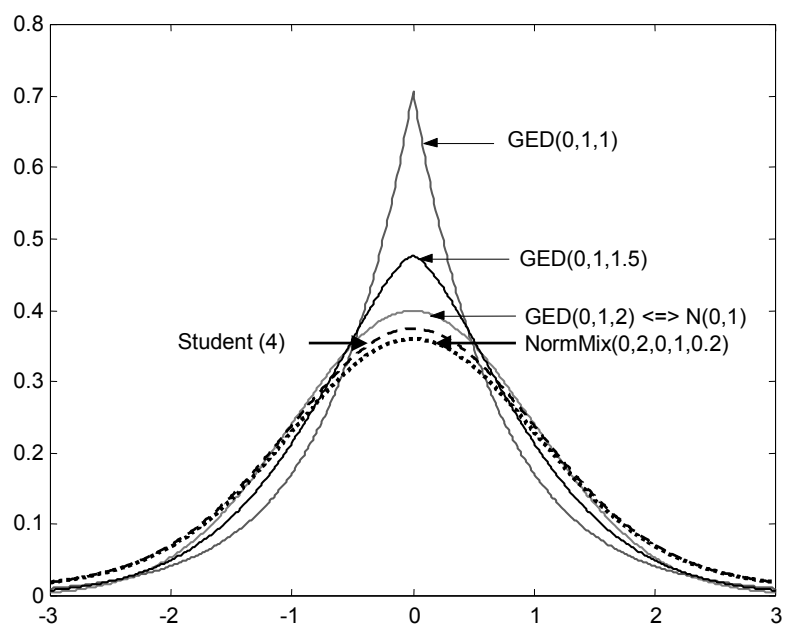

Figure 3. Sample density functions for examined distributions

Source: own study. 
Figure 3 shows sample density functions for the distributions examined in the study. What is relevant here are the various concepts regarding random noise modeling, particularly in the areas of the so-called "fat tails". In this case, taking into account previous experience, we can conclude that significantly better indications are obtained for models where the aforementioned random noises are modeled by fat-tailed distributions, i.e. those which more effectively handle extreme observations.

\section{Analysis of the Results}

The investigation of the decay factor properties in the process of forecasting future losses took into consideration a study group consisting of companies which in 2013 were listed at WIG20 index, i.e. stock exchange listed entities with highest capitalization at that time. The analysis took into account quotations from the period of three years, which constituted approx. 750 historical observations. Importantly, all calculations were performed at the significance level of $\alpha=0.05$.

All VaR estimations were computed using VaR calculator $^{1}$ software, while parameters necessary for these estimations were determined with OxEdit software. As mentioned previously, parameters of the investigated models were calculated using the maximum likelihood method. The optimal values of the decay factor for the respective models are shown in Table 1 . Generally, $\lambda$ values ranged from 0.9 to 1.0 (except for a few cases), hence the values of the decay factor taken into account in the analysis were in this range, and the values changed every 0.005 . This produced 21 different levels of the value.

Table 1. Values of decay factor $\lambda$ for specific models

\begin{tabular}{|c|c|c|}
\hline & RiskMetrics Normal Drift Model & RiskMetrics t-Student Model \\
\hline AssecoPol & 0,954389 & 0.944217 \\
\hline Bank Handlowy & 0,954373 & 0.946680 \\
\hline Bogdanka & 1.002350 & 0.963477 \\
\hline Boryszew & 0.990841 & 0.782848 \\
\hline BRE Bank & 0.914552 & 0.927885 \\
\hline GTC & 0.978482 & 0.963360 \\
\hline Jastrzębska Spółka Węglowa & 0.927996 & 0.919487 \\
\hline Kernel & 0.965543 & 0.944696 \\
\hline KGHM & 1.001530 & 0.939152 \\
\hline Lotos & 0.955977 & 0.957096 \\
\hline Pekao & 0.944536 & 0.945461 \\
\hline PGE & 0.926529 & 0.920565 \\
\hline PGNiG & 0.935948 & 0.945786 \\
\hline PKN Orlen & 0.954468 & 0.954791 \\
\hline PKO BP & 0.937841 & 0.940392 \\
\hline PZU & 0.951695 & 0.958898 \\
\hline Synthos & 0.938880 & 0.959520 \\
\hline Tauron Polska Energia & 0.935243 & 0.885797 \\
\hline TP S.A. & 1.001980 & 0.980830 \\
\hline TVN & 0.938435 & 0.961627 \\
\hline \multirow[t]{2}{*}{ Mean } & 0.955579 & 0.937128 \\
\hline & RiskMetrics NormalMixture Model & RiskMetrics GED Model \\
\hline AssecoPol & 0.918641 & 1.002090 \\
\hline Bank Handlowy & 0.930069 & 0.948311 \\
\hline Bogdanka & 0.851728 & 1.001220 \\
\hline Boryszew & 0.736877 & 0.994859 \\
\hline BRE Bank & 0.900436 & 0.922980 \\
\hline GTC & 0.957721 & 0.967670 \\
\hline Jastrzębska Spółka Węglowa & 0.866749 & 0.925009 \\
\hline Kernel & 0.924287 & 1.004840 \\
\hline KGHM & 0.935228 & 0.940196 \\
\hline Lotos & 0.948923 & 0.956758 \\
\hline Pekao & 0.940240 & 0.944258 \\
\hline PGE & 0.907382 & 0.923163 \\
\hline
\end{tabular}




\begin{tabular}{lcc}
\hline PGNiG & 0.907585 & 0.944867 \\
PKN Orlen & 0.935015 & 0.955564 \\
PKO BP & - & 0.940204 \\
PZU & 0.927072 & 0.955083 \\
Synthos & 0.894264 & 0.957255 \\
Tauron Polska Energia & 0.839022 & 0.914141 \\
TP S.A. & - & 0.986180 \\
TVN & 0.931236 & 0.952498 \\
Mean & 0.902915 & 0.956857 \\
\hline
\end{tabular}

Source: own study.

It is clear that the most varied values for the decay factor, determined with the maximum likelihood method, were found for Boryszew Company and Tauron Polska Energia. For the former, the values of $\lambda$ reach the level of 0.736877 in RiskMetrics NormalMixture model.

Apart from the optimal values of the decay factor, as shown above, the study investigated effectiveness of the models in question in the case of changing $\lambda$ levels. The assessment was performed by analyzing the percentage of exceedances beyond the acceptable VaR threshold, which is $5 \%$ in this case. The obtained estimates can be seen in Figures 4-7.

Importantly, $\lambda$ is commonly referred to as the information decay factor. It simply defines the weight for the latest observations and the speed with which the measure of volatility adjusts to empirical changes. Hence, lower values of the factor coincide with higher weight of the latest changes, and more rapid adjustment of volatility rate to changes in time series.

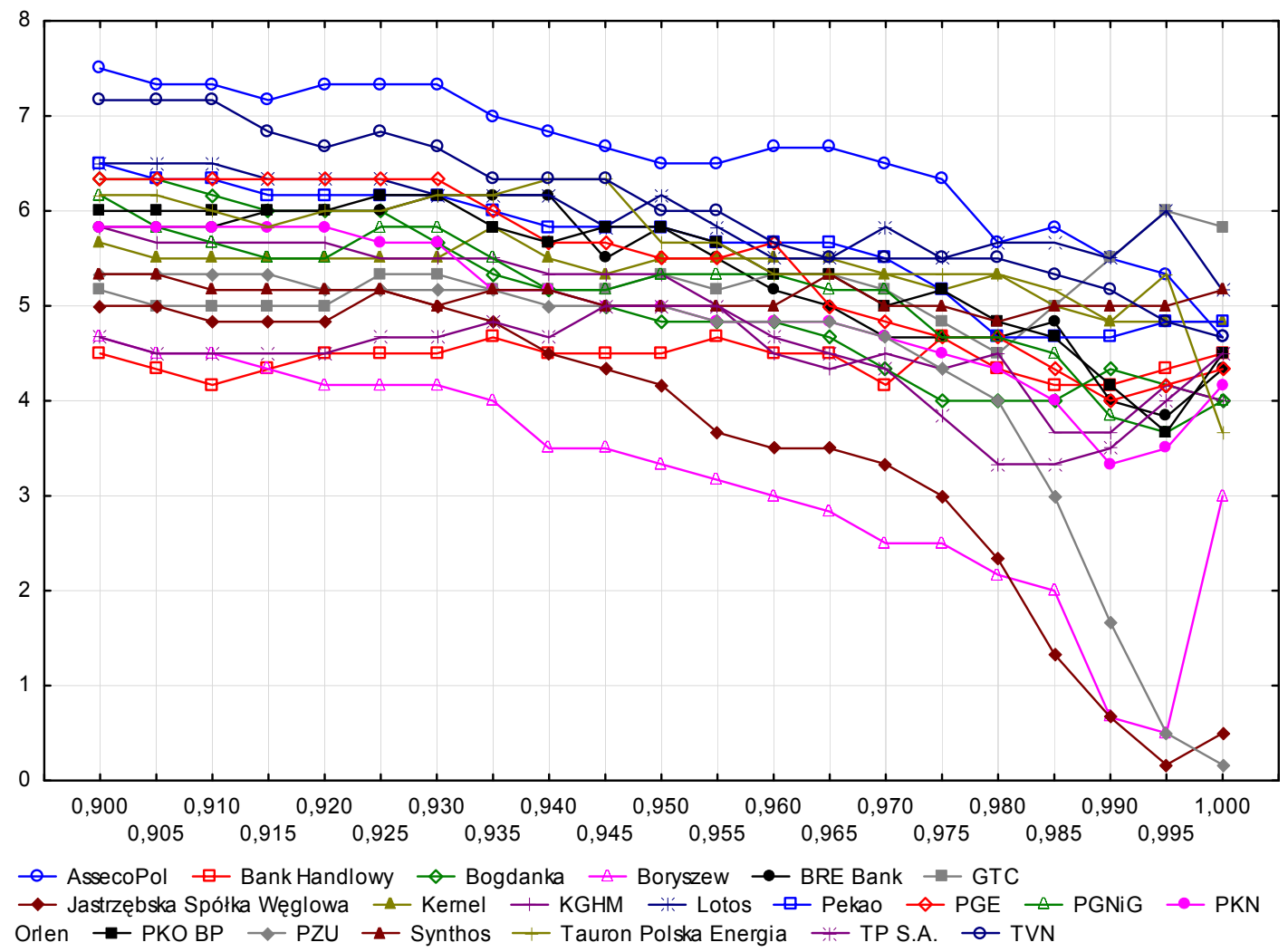

Figure 4. Percentage of exceedances of the acceptable VaR threshold (5\%) for RiskMetrics Normal Drift model, relative to the changing decay factor values

Source: own study. 
The choice of $\lambda$ factor is of critical importance for EWMA. Generally, different (lower) values are used for daily volatility indices, than for example for monthly ratings (these are higher). Higher level of $\lambda$ is used to obtain average long-term volatility and, accordingly, lower rate of $\lambda$ can be applied to examine volatility within shorter periods (Figure 1). For instance, in the case of one-day periods measure of volatility takes into account significant and rapid decay of information, hence it is based on the latest observations in the historical series. Yet, it provides for better adjustment to actual data.

An analysis of the findings suggests that generally an increase in the value of the decay factor has a rather positive impact on information provided by Value-at-Risk models, at least at the first glance, if we examine exclusively the percentage of exceedances beyond the threshold value. This may result in overstatement of potential losses, which consequently may lead to greater aversion to risk. In fact, intuitively, higher $\lambda$ values should contribute to smoothing of the series by increasing the significance of information, which is more distant in terms of time. Hence, the degree to which Value at Risk matches current events in the market should gradually become lower. Additionally Figures 4-7 show overall assessment of information provided by the specific models. Generally speaking, it is possible to confirm the superiority of the model in which random noises were modeled using Student's t-distribution. Here, relatively poor effectiveness was found in the case of the classic RiskMetrics model, where random noises are modeled by normal distribution. By comparison with the latter, better results are acquired with RiskMetrics GED, which is sensitive to changes in the levels of significance (Mentel, 2011b).

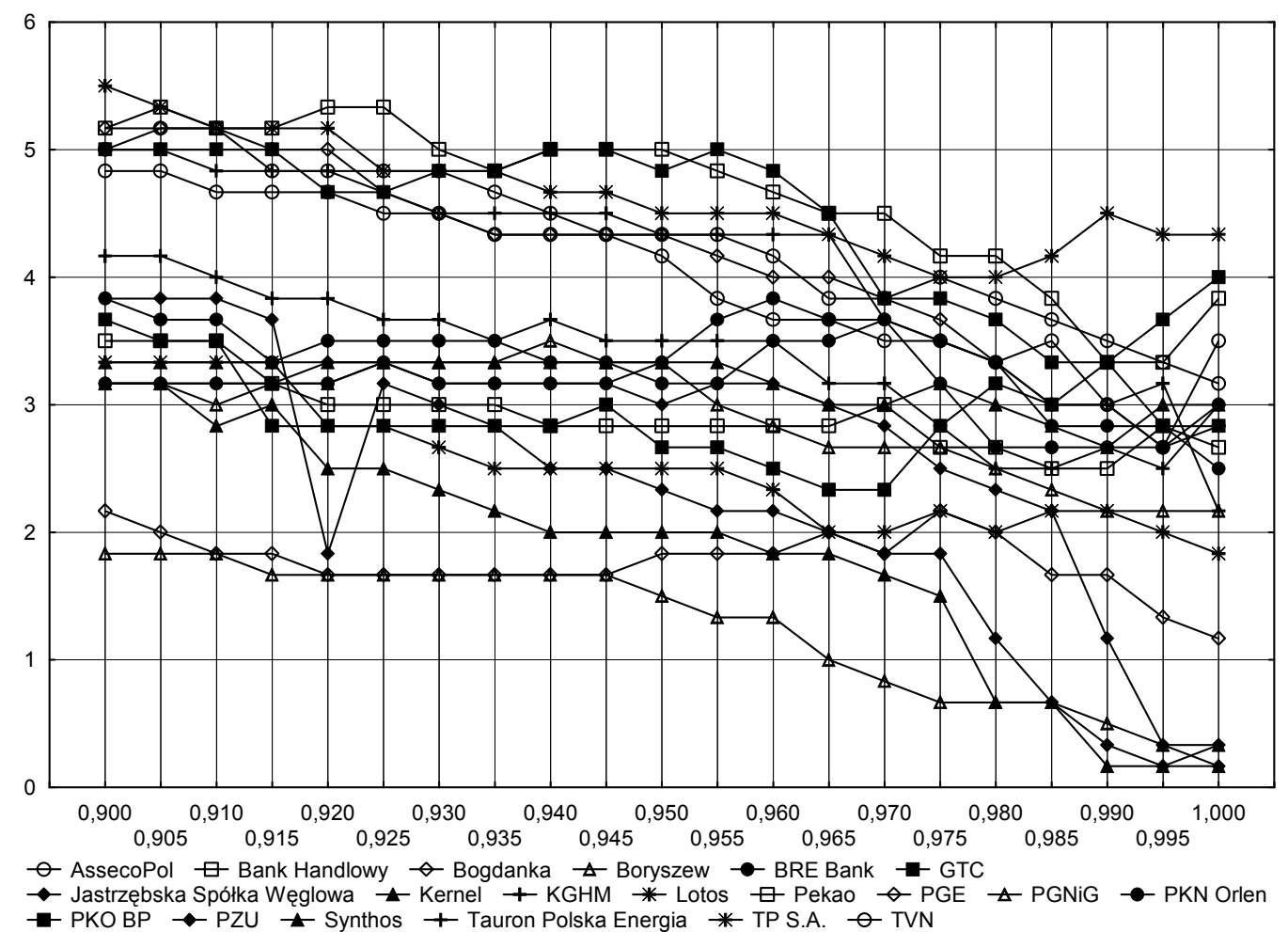

Figure 5. Percentage of exceedances of the acceptable VaR threshold (5\%) for RiskMetrics t-Student model, relative to the changing decay factor values

Source: own study. 


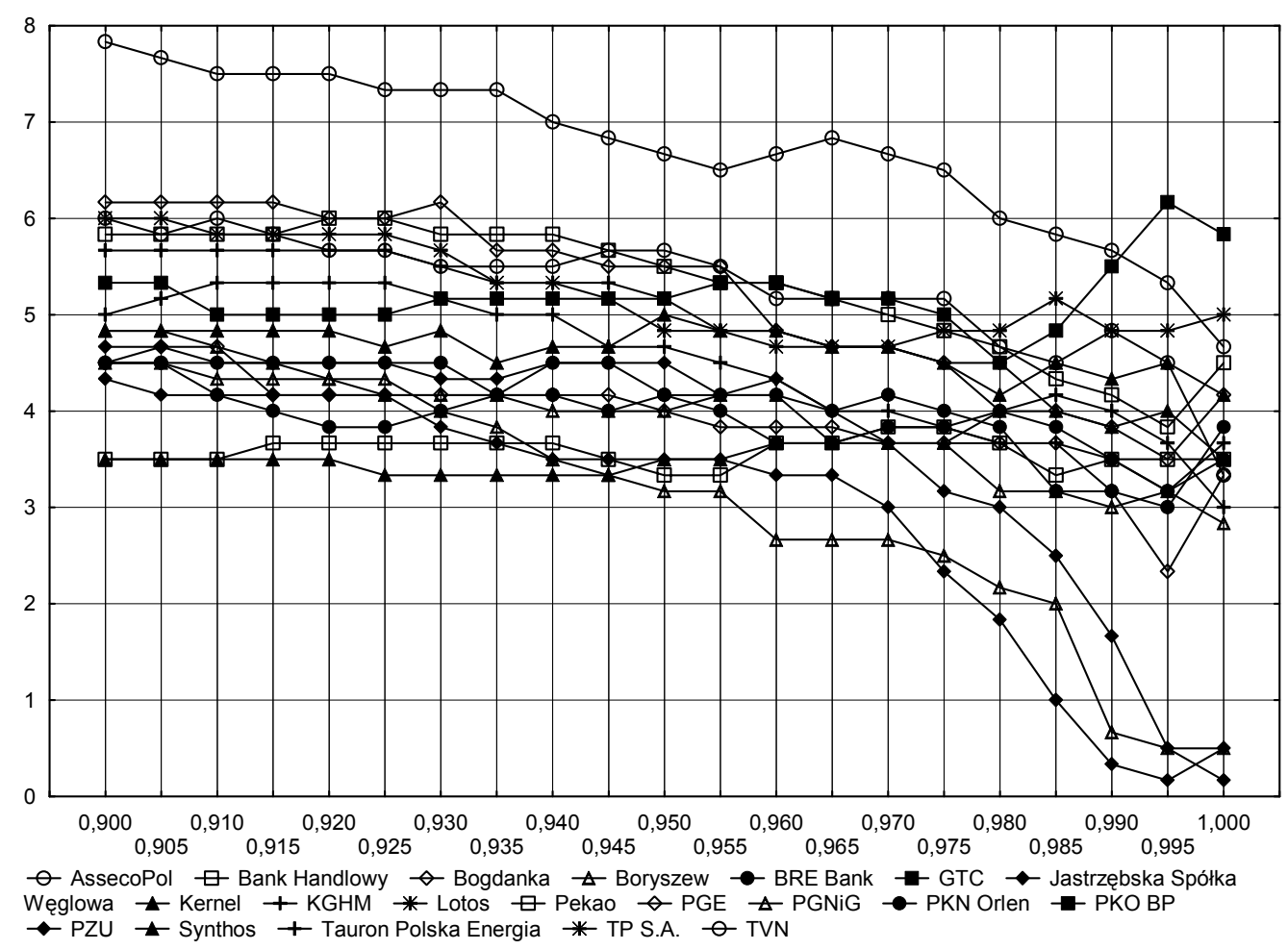

Figure 6. Percentage of exceedances of the acceptable VaR threshold (5\%) for RiskMetrics NormalMixture model, relative to the changing decay factor values

Source: own study.

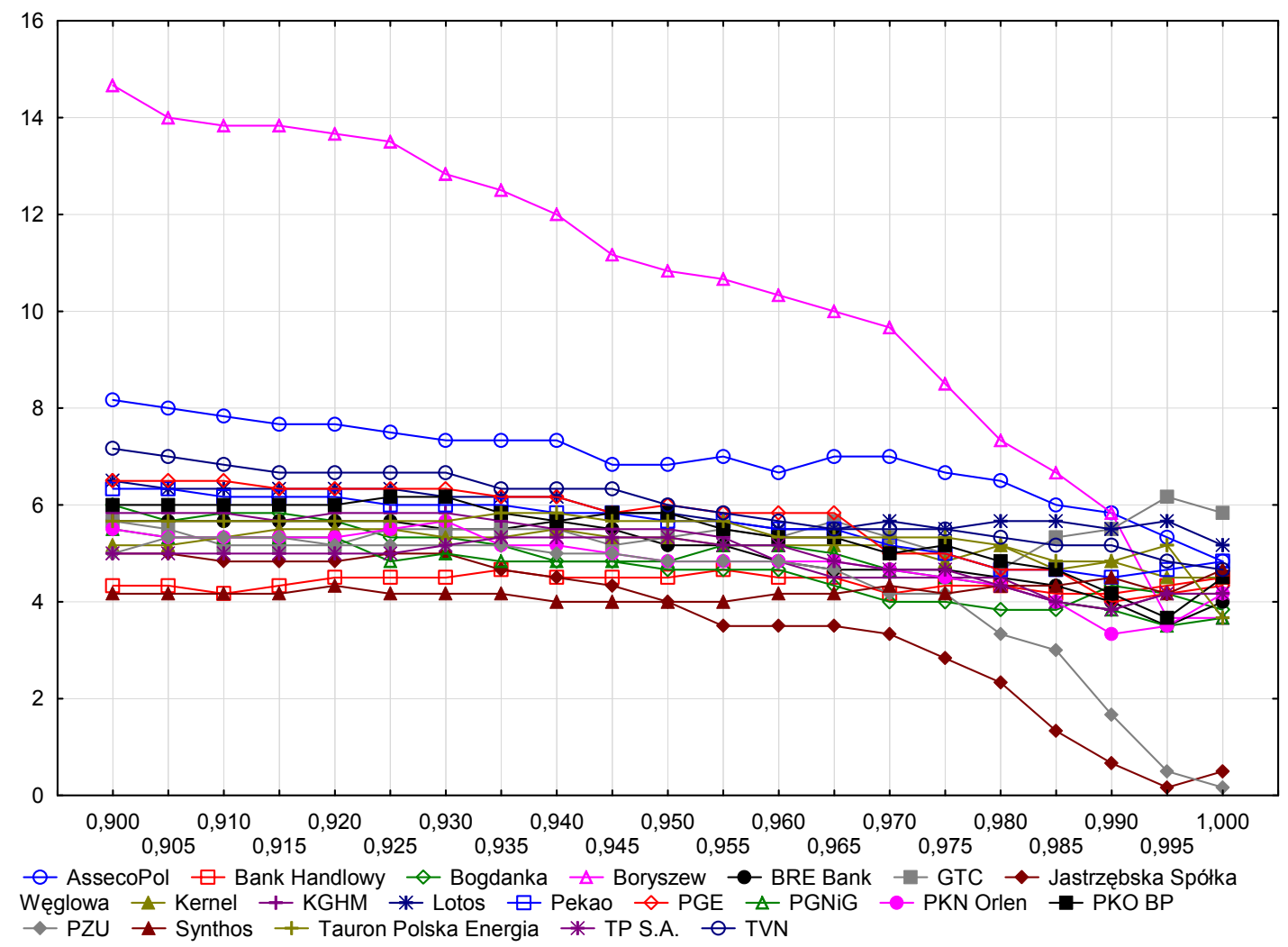

Figure 7. Percentage of exceedances of the acceptable VaR threshold (5\%) for RiskMetrics GED model, relative to the changing decay factor values

Source: own study. 
The performed analysis shows that entities respond to changes in the decay factor in various ways. Those most impressionable are Boryszew, Jastrzębska Spółka Węglowa and PZU. In their case the final indications are quite significantly affected by $\lambda$. It would be a good idea to examine quotations of these companies in the relevant period.

Yet, given the fact that the number of historical observations taken into account in the study was constant, and changes were made only in the decay factor values, it would be a good idea to examine not only the percentage of exceedances yielded by the specific methods but also the values of potential losses. Otherwise, the previously formulated hypothesis suggesting that an increase in $\lambda$ should improve the general quality of estimations would be correct, yet this is not true. Due to the large number of entities and methods, the phenomenon was depicted using the example of TVN Company, in the context of the optimal method, i.e. RiskMetrics t-Student (Figure 8) for year 2012. To increase the clarity of the graph, VaR curves were shown for $\lambda$ values ranging from 0.90 to 0.99 (step 0.01). The initially determined optimal decay factor for this example is 0.96 .

Even superficial analysis allows a conclusion that the decay factors determined by means of the maximum likelihood method are not optimal. Good results, for all four models in question, are obtained for $\lambda=0.97$, i.e. the factor based on the initially defined number of historical observations which was assumed for further considerations. Additionally, its value should be treated more on a case-by-case basis, because every study group may include elements which will not support the rule. There is also confirmation for the earlier suggestion that an increase in the decay factor coincides with increased smoothing of probable losses, which results in less pronounced changes in comparison with events occurring in the market. Because VaR becomes less flexible, in this case, it frequently leads to overestimation of potential losses and unduly increased aversion to risk exhibited by potential investors.

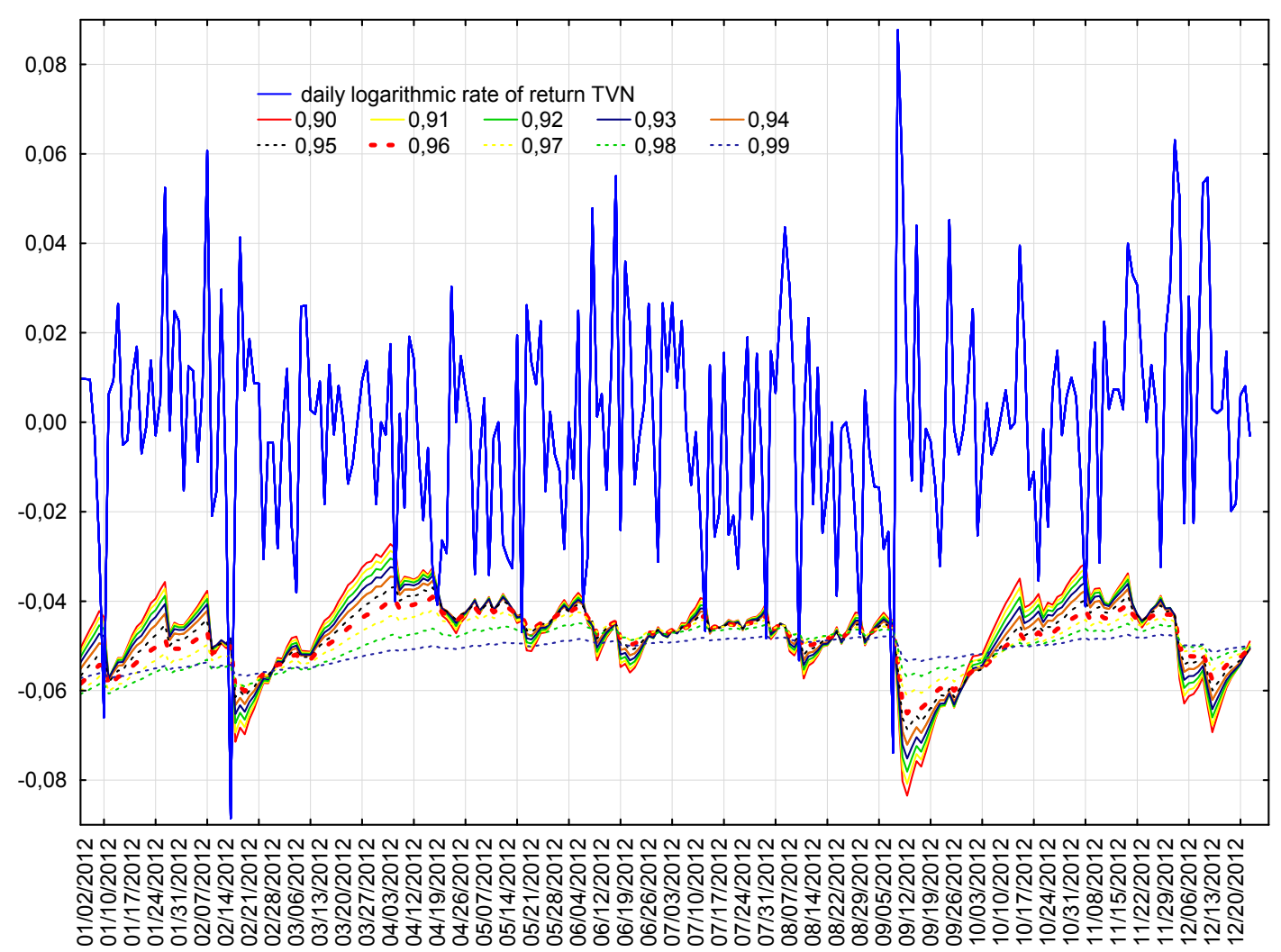

Figure 8. Values at Risk for TVN in 2012 determined using RiskMetrics $t$-Student method for various levels of $\lambda$

Source: own study.

\section{Conclusions}

Throughout the price change forecasting process it is necessary to constantly remember about the determinants of the applied models, since these are susceptible to changes in some factors, such as the level of significance or 
number of historical observations. In addition to these, an important problem is related to assignment of weights to returns from various periods. Due to the existing autocorrelation, accurate determination of current volatility is more significantly affected by returns from the recent periods than by earlier returns. Yet, there is a question, what significance should be assigned to specific items of information.

It seems the proposed exponentially weighted moving average is more adequate in this case than GARCH class models, since these assign higher weight to returns from the latest periods, which is not always a correct assumption. We should remember that EWMA is a kind of variation to Generalized Autoregressive Conditional Heteroskedastic method. $\beta$ parameter in GARCH corresponds to information decay factor $\lambda$ in EWMA, while, respectively, $\lambda$ corresponds to element $(1-\lambda)$. Regardless of the selected variant, what is important is the fact that these methods do not adopt an assumption of constant volatility.

Assessment of the findings related to information decay process allows a few conclusions. This is because:

- increase in the decay factor value results only in an apparent improvement in the quality of Value at Risk indications. Therefore, attaching too much attention to historically distant observations does not produce good results, hence the general assumption that most attention should be attached to the latest events is gaining significance;

- a change in $\lambda$ does not produce the same level of response in all entities. The study group in question contained companies for which small changes in the decay factor level produced significant differences in relation to earlier indications. Such situation can mainly be observed for value of $\lambda>0,96$;

- $\quad$ large values of $\lambda$ excessively smooth away value at risk, whereby it becomes less flexible and its shape increasingly diverges from actual market changes.

- even if they are estimated by means of the maximum likelihood method, like in this case, the "optimal" decay factors do not always produce the best approximations,

- $\quad$ by comparison with the other methods, $\lambda$ proposed by RiskMetrics ${ }^{\mathrm{TM}}$ for one-day data seems to be a correct proposal.

\section{References}

Best, P. (2000). Wartość narażona na ryzyko. Dom Wydawniczy ABC, Kraków.

Bollersev, T. (1986). Generalized Autoregressive Conditional Heteroscedasticity. Journal of Econometrics, 31. http://dx.doi.org/10.1016/0304-4076(86)90063-1

Bollersev, T. (1987). A Conditional Heteroskedastic Model for Speculative Prices and Rates of Return. Review of Economics and Statistics, 69. http://dx.doi.org/10.2307/1925546

Crowder, S. V. (1987). Run-Lenght Distributions of EWMA Charts. Technometrics, 29.

Jongwoo, K., \& Mina, J. (2001). RiskGrades ${ }^{\mathrm{TM}}$ Technical Document (2nd ed.). New York.

Mentel, G. (2011a). RiskMetrics ${ }^{\mathrm{TM}}$ Methodology in Assessment of Investment Risk on Capital Market. Folia Oeconomica Stetinensia, 9(17).

Mentel, G. (2011b). Value at Risk w warunkach polskiego rynku kapitałowego. Wydawnictwa Fachowe CeDeWu, Warszawa.

Mentel, G. (2013). Parametric or Non-Parametric Estimation of Value at Risk. International Journal of Business and Managament, $8(11)$.

Mentel, G., \& Brożyna, J. (2014). Historical Data in the Context of Risk Prediction. International Journal of Business and Social Research, 3(1).

Mina, J., \& Yi, C. J. (2001). Return to Risk Metrics: The Evalution of a Standard. RiskMetrics Technical Documents, Nowy Jork.

Pisula, T., \& Pisula, J. (2001). Jak efektywnie przewidywać ryzyko zmian kursów akcji spółek notowanych na Warszawskiej Giełdzie Papierów Wartościowych. Oficyna Wydawnicza Politechniki Rzeszowskiej, Rzeszów.

\section{Note}

Note 1. VaR calculator http://prz.edu.pl/ jacekb/software/freeware/VaR/ 


\section{Copyrights}

Copyright for this article is retained by the author(s), with first publication rights granted to the journal.

This is an open-access article distributed under the terms and conditions of the Creative Commons Attribution license (http://creativecommons.org/licenses/by/3.0/). 